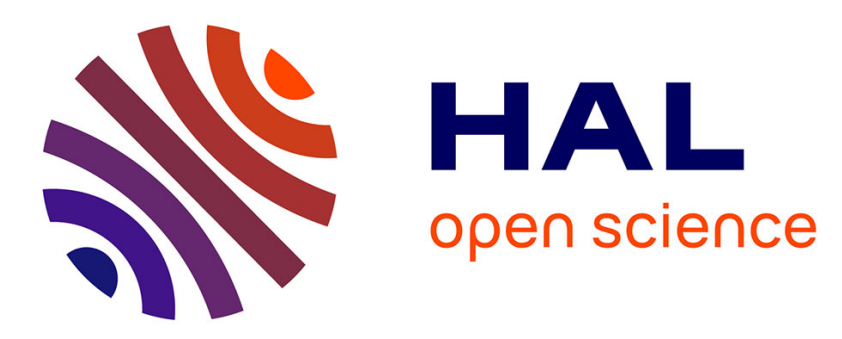

\title{
Magnetically affected texture and microstructure evolution during grain growth in zirconium
}

\author{
Dmitri A. Molodov, Nathalie Bozzolo
}

\section{To cite this version:}

Dmitri A. Molodov, Nathalie Bozzolo. Magnetically affected texture and microstructure evolution during grain growth in zirconium. 4th International Conference on Recrystallization and Grain Growth, ReX and GG IV, Jul 2010, Sheffield, United Kingdom. pp.Pages 946-951 - edited by E.J. Palmiere and B.P. Wynne, 10.4028/www.scientific.net/MSF.715-716.946 . hal-00700724

HAL Id: hal-00700724

https: / hal-mines-paristech.archives-ouvertes.fr/hal-00700724

Submitted on 23 Aug 2012

HAL is a multi-disciplinary open access archive for the deposit and dissemination of scientific research documents, whether they are published or not. The documents may come from teaching and research institutions in France or abroad, or from public or private research centers.
L'archive ouverte pluridisciplinaire HAL, est destinée au dépôt et à la diffusion de documents scientifiques de niveau recherche, publiés ou non, émanant des établissements d'enseignement et de recherche français ou étrangers, des laboratoires publics ou privés. 


\title{
Magnetically affected texture and microstructure evolution during grain growth in Zirconium
}

\author{
Dmitri A. Molodov ${ }^{1, a}$, Nathalie Bozzolo 2,3,b \\ ${ }^{1}$ Institute of Physical Metallurgy and Metal Physics, RWTH Aachen University, \\ 52056 Aachen, GERMANY \\ ${ }^{2}$ LETAM (Laboratoire d'Etude des Textures et Application aux Matériaux), FRE CNRS 3143, \\ Université Paul Verlaine - Metz, Ile du Saulcy, F-57045 Metz Cedex, France \\ ${ }^{3}$ MINES ParisTech, CEMEF - Centre de Mise en Forme des Matériaux, UMR CNRS 7635, \\ 1 rue Claude Daunesse 06904 Sophia Antipolis cedex, France \\ a molodov@imm.rwth-aachen.de, ${ }^{\mathrm{b}}$ nathalie.bozzolo@mines-paristech.fr
}

Keywords: Grain growth, Magnetic annealing, Zirconium, Magnetic anisotropy.

\begin{abstract}
The effect of a magnetic field on texture and microstructure development in cold rolled $(80 \%)$ commercially pure zirconium (Zr701) was investigated. The specifically oriented sheet specimens were annealed at $550^{\circ} \mathrm{C}$ for different times in a magnetic field of $19 \mathrm{~T}$ and $17 \mathrm{~T}$, respectively. X-ray diffraction and EBSD measurements were utilized for the texture and microstructure characterization. The results revealed that a magnetic field promotes grain growth in the investigated material. During annealings at $550^{\circ} \mathrm{C}$ this is particularly apparent from the faster development of specific $(0 / 180,35,30)$ texture components and the bigger mean grain size after magnetic annealing. The magnetic annealing at $700^{\circ} \mathrm{C}$ resulted in an asymmetry of the two major texture components. This is due to a magnetic driving force for grain growth arising from the anisotropic magnetic susceptibility of zirconium. During annealing at $700^{\circ} \mathrm{C}$ the abnormal grain growth occurred. This behaviour is attributed to the higher mobility of grain boundaries between grains misoriented by $30^{\circ}$ around [0001]. The magnetic field essentially enhanced the observed abnormal grain growth.
\end{abstract}

\section{Introduction}

It was shown in experiments on bismuth and zinc bicrystals [1-8] that grain boundaries in non-ferromagnetic metals can be moved by a specific driving force that arises in the presence of a magnetic field due the magnetic anisotropy of the material. This force $\mathrm{p}_{\mathrm{m}}^{\mathrm{b}}$ acting on the boundary of two crystals with different magnetic susceptibility $\chi$ along the field direction and consequently different magnetic energy density $\omega$, is given by [9]

$$
\mathrm{p}_{\mathrm{m}}^{\mathrm{b}}=\omega_{1}-\omega_{2}=\frac{\mu_{0} \mathrm{H}^{2}}{2} \chi_{1}-\chi_{2}=\frac{1}{2} \mu_{0} \Delta \chi \mathrm{H}^{2} \cos ^{2} \theta_{1}-\cos ^{2} \theta_{2},
$$

where $\mu_{0}$ is the magnetic constant, $\mathrm{H}$ is the magnetic field strength, $\Delta \chi$ is the difference of the susceptibilities parallel $\chi_{\| I}$ and perpendicular $\chi_{\perp}$ to the principal (or $c$ ) axis of the crystal, $\theta_{1}$ and $\theta_{2}$ are the angles between the $c$-axes in both neighboring grains and the magnetic field direction.

An effective magnetic driving force $\mathrm{p}_{\mathrm{m}}$ for growth or shrinkage of each grain in a polycrystal can be expressed as the difference between the magnetic free energy density of this grain $\omega$ and an average magnetic free energy density $\bar{\omega}$ of its neighboring grains :

$$
\mathrm{p}_{\mathrm{m}}=\omega-\bar{\omega}=\frac{\mu_{0} \mathrm{H}^{2}}{2}\left(\chi-\frac{1}{\mathrm{n}} \sum_{\mathrm{j}}^{\mathrm{n}} \chi_{\mathrm{j}}\right)=\frac{1}{2} \mu_{0} \Delta \chi \mathrm{H}^{2}\left(\cos ^{2} \theta-\frac{\sum_{\mathrm{j}}^{\mathrm{n}} \cos ^{2} \theta_{\mathrm{j}}}{\mathrm{n}}\right)
$$


where $\theta$ and $\theta_{j}$ are the angles between the field direction and principal axes of the considered grain and its $\mathrm{n}$ neighboring grains. The orientation dependence of the magnetic driving force provides an opportunity to impact the grain orientation distribution in a polycrystal and thus allows one to use a magnetic field as additional degree of control of crystallographic texture and microstructure evolution during grain growth. This was proved experimentally first on polycrystalline cold-rolled $\mathrm{Zn}$ $1 \% \mathrm{Al}$ alloy [10] and then on commercially pure Ti $[11,12]$ as well as by computer simulations of $2 \mathrm{D}$ grain growth in Ti $[12,13]$.

The current paper represents an experimental investigation into the influence of a magnetic field on texture and grain microstructure evolution during grain growth in zirconium.

\section{Experimental}

A sheet (3.6 mm in thickness) of commercially pure zirconium ( $\mathrm{Zr} 701)$ previously hot rolled in the range between $930^{\circ} \mathrm{C}$ and $960^{\circ} \mathrm{C}$, then cold-rolled and finally annealed at $630^{\circ} \mathrm{C}$ was rolled at room temperature to a final thickness of $0.7 \mathrm{~mm}$, equivalent to a reduction of $80 \%$.

Specimens of the cold rolled sheet $\left(13 \times 12 \mathrm{~mm}^{2}\right)$ were annealed at $550^{\circ} \mathrm{C}$ for 15,30 and $45 \mathrm{~min}$ and at $700^{\circ} \mathrm{C}$ for 60,90 and $180 \mathrm{~min}$ in a magnetic field of $19 \mathrm{~T}$ and $17 \mathrm{~T}$, respectively. Reference specimens were annealed at the same temperature for the same time at zero field (except for the reference specimen for 90 min magnetic annealing, which was annealed at zero field for $120 \mathrm{~min}$ ). To avoid an oxidation, the specimens were encapsulated in a vacuum of $2 \times 10^{-5} \mathrm{~Pa}$ in quartz tubes before annealing. The temperature during annealing was kept constant within a range of $\pm 2{ }^{\circ} \mathrm{C}$.

In order to affect the texture and microstructure evolution by applying a magnetic field, the specimens were annealed in a tilted position with respect to the field direction. The rolling direction was normal to the field, whereas the transverse direction was tilted around the rolling direction by $32^{\circ}$ with respect to the field direction. A tilt angle of $32^{\circ}$ ensures that the c-axes of grains which compose one of the two annealing texture components (Figs. 1,2) are aligned nearly normal to the field direction.

Crystallographic texture and microstructure were characterized in the mid-layer of the sheet before and after annealing by X-ray pole figure measurements and orientation imaging microscopy by EBSD in a FEG-SEM. The orientation distribution functions (ODFs) were determined from a set of six incomplete pole figures (0002), $\{10 \overline{10}\},\{1 \overline{1} \overline{0}\},\{10 \overline{1}\},\{10 \overline{1} 2\}$ and $\{10 \overline{1}\}$ measured with Co $\mathrm{K}_{\alpha}$ radiation by means of a fully automated texture goniometer in back reflection mode. The ODFs were computed by using the series expansion method with positivity criterion $[14,15]$. The sample symmetry was regarded triclinic to account for asymmetric textures after annealing in the magnetic field. The measurement step size for orientation imaging by EBSD was adapted to the microstructure scale and was chosen to be about one tens of the mean grain size. The mean grain size is calculated as the average value of the equivalent circle diameters associated to all detected grains (groups of at least five neighboring pixels with less than $5^{\circ}$ disorientation).

\section{Results}

Magnetically affected texture and grain microstructure after annealing at $550^{\circ} \mathrm{C}$. The coldrolling texture with two peaks in the (0002) pole figure measured after $80 \%$ reduction is similar to those already reported in literature for low alloyed zirconium after high rolling reductions [16,17]. This is characterized by two major ODF peaks widely spread around the orientations $\left(\varphi_{1}, \Phi, \varphi_{2}\right)=$ $\{(0,25,0)$ and $(180,25,0)\} .\left(\varphi_{1}, \Phi, \varphi_{2}\right)$ are Euler angles determined according to Bunge's definition and with $\mathrm{X}=[10 \overline{1} 0], \mathrm{Y}=[\overline{1} 2 \overline{1} 0], \mathrm{Z}=[0001]$ as a crystal coordinate system.

Annealing at $550^{\circ} \mathrm{C}$ for $15 \mathrm{~min}$ and more resulted in practically fully recrystallized structure, which after 15 and 45 min annealing mostly comprised equiaxed grains with a mean grain size of $4.9 \mu \mathrm{m}$ and $5.9 \mu \mathrm{m}$, respectively. 
As evident from two symmetrical basal pole density maxima in the (0002) pole figures (Fig. 1a), the texture obtained after conventional annealing at $550^{\circ} \mathrm{C}$ retained some features of the deformation texture, i.e. comprises two peaks related to [0001] axes tilted by $+35^{\circ}$ or $-35^{\circ}$ from ND in the ND-TD plane, and is characterized by the high intensity ODF peaks at the orientations $(0 / 180$, $\left.35, \varphi_{2}\right)$ as well as the lower intensity fiber $\left(\varphi_{1}, 0, \varphi_{2}\right)$ (Fig. 1$)$.

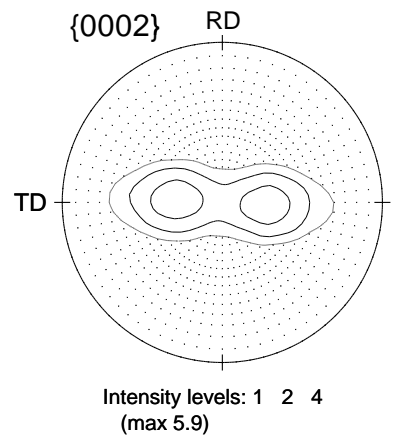

a

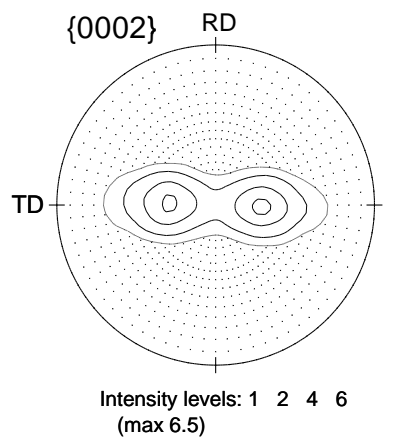

$\mathrm{b}$

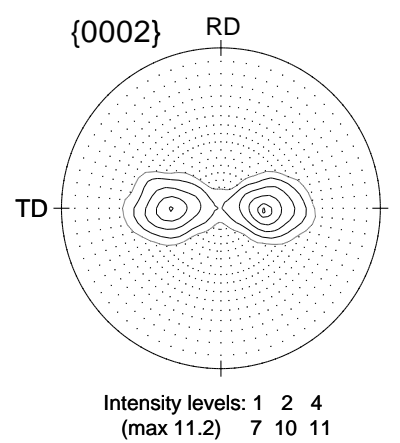

c

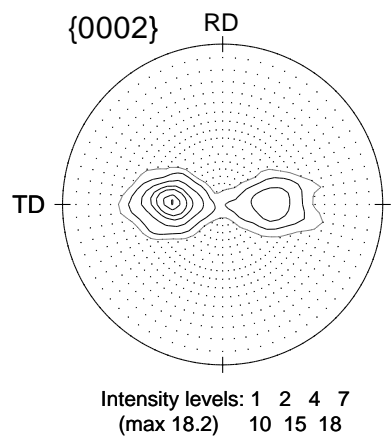

d

Fig. 1. (0002) pole figures for specimens annealed at $550^{\circ} \mathrm{C}$ for $45 \mathrm{~min}$ (a) at zero field, (b) in a magnetic field of $19 \mathrm{~T}$, and for specimens annealed at $700^{\circ} \mathrm{C}$ for (c) $120 \mathrm{~min}$ at zero field and (d) 90 min in a magnetic field of $17 \mathrm{~T}$.

Annealing in a magnetic field of $19 \mathrm{~T}$ distinctly modified the texture, although the peaks in the (0002) pole figure remained symmetrical (Figs. 1a-b). The intensity of the peaks around the orientations $(0 / 180,35,30)$ increased, whereas the density of orientations close to $(0 / 180,30,0)$ decreased. Figure 2 depicts the orientation density along specific fibers containing major texture components after annealing at $550^{\circ} \mathrm{C}$ for $45 \mathrm{~min}$. As seen, the peak maximum in the $\varphi_{2}=30^{\circ}$ curves rises after annealing in a magnetic field, whereas the maxima in the $\varphi_{2}=0^{\circ}$ curves degrade. This behavior was observed for both components, i.e. $\varphi_{1}=0^{\circ}$ and $\varphi_{1}=180^{\circ}$ (Fig. 2), although the grains of the $\varphi_{1}=180^{\circ}$ component were favored and the grains of the $\varphi_{1}=0^{\circ}$ - component were disfavored for growth by a difference in the magnetic energy density between differently oriented grains. This indicates that the observed texture changes were not caused by the magnetic driving force. In fact, at the early stage of grain growth it is much smaller than the curvature driving force [18]. For the current experiment it can be shown that the magnetic force during annealing at $550^{\circ} \mathrm{C}$ is at least by a factor of 5 smaller than the curvature driving force and, therefore, cannot distinctly affect growth of favourably oriented grains. Indeed, the both texture components after annealing at $550^{\circ} \mathrm{C}$ in the field remain symmetrical (Fig. 1b).

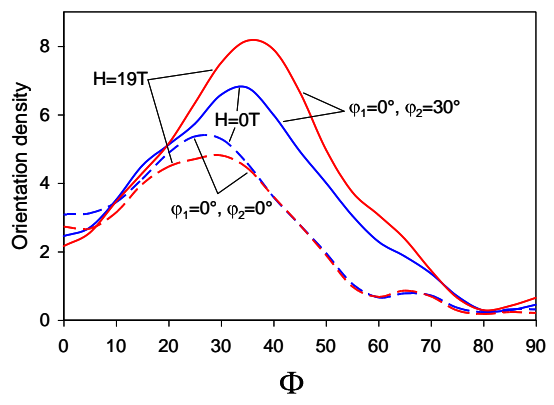

a

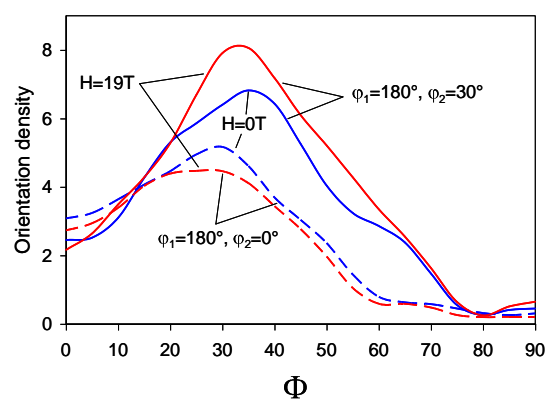

b

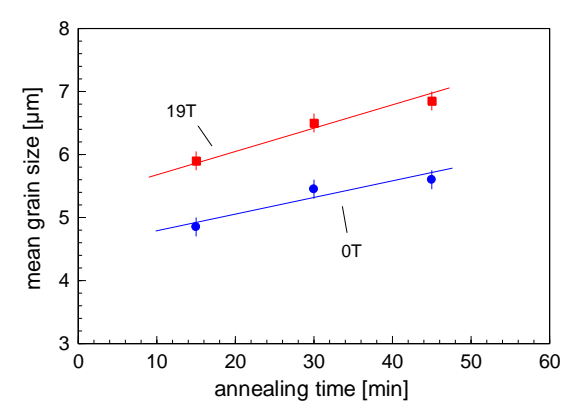

c

Fig. 2. Orientation density along the fibers a) $\varphi_{1}=0^{\circ}, \varphi_{2}=0^{\circ}$ as well as $\varphi_{1}=0^{\circ}, \varphi_{2}=30^{\circ}$, and b) $\varphi_{1}=180^{\circ}, \varphi_{2}=0^{\circ}$ as well as $\varphi_{1}=180^{\circ}, \varphi_{2}=30^{\circ}$ after annealing at $550^{\circ} \mathrm{C}$ for $45 \mathrm{~min}$ at zero field and at $19 \mathrm{~T}$, respectively; c) mean grain size vs. annealing time for specimens annealed at $550^{\circ} \mathrm{C}$ without field and in a field of $19 \mathrm{~T}$. 
A simultaneous increase of the peak maximum on the curves of $\varphi_{2}=30^{\circ}$ and a decrease of this on the curves of $\varphi_{2}=0^{\circ}$ (Fig. 2a,b ) suggests that the components $(0 / 180,35,30)$ develop from the $(0 / 180,30,0)$ rolling texture components. As observed in the study by Dewobroto et al. [16], the development of the $(0 / 180,25,30)$ components at the expense of the $(0 / 180,30,0)$ components is a result of the progressive grain growth during annealing of cold rolled low alloyed zirconium sheet. Therefore, the texture changes observed in the current experiment after magnetic annealing at $550^{\circ} \mathrm{C}$ (Figs. 1,2) indicate that a magnetic field enhances grain growth in the investigated material. A promotion of grain growth by a magnetic field is also apparent from magnetically induced grain microstructure alteration: the mean grain size after magnetic annealing is distinctly larger than after annealing in zero field (Fig. 2c).

The results of annealings of cold rolled $\mathrm{Zr}$ sheet at $550^{\circ} \mathrm{C}$ provide further evidence that the impact of an external magnetic field on the texture and microstructure evolution must not be necessarily associated with a magnetic driving force for grain boundary motion, but can be caused by an enhanced ability of grain boundaries to move, i.e. increased grain boundary mobility. Similar enhancement of the growth kinetics and magnetically induced texture changes were recently observed at early stages of grain growth in cold rolled (78\%) commercially pure titanium [19].

Magnetically affected texture and grain microstructure after annealing at $700^{\circ} \mathrm{C}$. The grain growth texture after annealing at $700^{\circ} \mathrm{C}$ out of magnetic field for 60,120 and $180 \mathrm{~min}$ is characterized by two major ODF peaks at $(0,35,30)$ and $(180,35,30)$ with similar intensities and correspondingly a nearly symmetrical (0002) pole figure (Fig. 1c). After magnetic annealing of $\mathrm{Zr}$ specimens at $700^{\circ} \mathrm{C}$ the peaks in the $(0002)$ pole figure become strongly asymmetrical (Fig. 1d). The ODF intensity at the $\left(180,35, \varphi_{2}\right)$ orientations exceeds essentially the corresponding intensity after annealing without field.

The information on the grain microstructure with respect to grain size and number of grains composing different texture components obtained by orientation imaging with EBSD is given in Table 1. For analysis of EBSD data the whole set of grains was subdivided into subsets A, B, C and D with orientations around $(0,35,0),(0,35,30),(180,35,0)$ and $(180,35,30)$, respectively. $\mathrm{A} 15^{\circ}$ tolerance was applied so that any grain disoriented by less than $15^{\circ}$ with each of those ideal orientations was included in the corresponding subset. The subsets $\mathrm{A}+\mathrm{B}$ and $\mathrm{C}+\mathrm{D}$ essentially represent the two texture peaks in the (0002) pole figures in Fig. 1. In addition, Table 1 gives also the number and mean size of grains with c-axes tiled on the left (subset L) and right (subset R) side of the (0002) pole figure.

The results reveal that also at $700^{\circ} \mathrm{C}$ the growth kinetics of all grains are enhanced by a magnetic field. As seen in Table 1, there is no difference in the mean grain size for grains in grain subsets $\mathrm{A}+\mathrm{B}$ and $\mathrm{C}+\mathrm{D}$ or $\mathrm{R}$ and $\mathrm{L}$ in specimens annealed without field. By contrast, in specimens after magnetic annealing the mean size of grains in the subset $C+D(40.4 \mu \mathrm{m})$ is larger than in the subset $A+B$ $(33.6 \mu \mathrm{m})$. A magnetic annealing also alters the number of grains in the different grain subsets. As seen in Table 1, after 180 min annealing in a field the subsets $\mathrm{C}+\mathrm{D}$ and $\mathrm{L}$ comprise much more grains (1166 and 2971) than the subsets A+B (802) and R (1886).

Apparently, the observed pronounced asymmetry in the (0002) pole figures (Fig. 1d) is caused by the impact of the magnetic driving force on grain growth. With increasing grain size, the curvature driving force decreases and becomes comparable with the magnetic driving force: the estimate shows that for the grain size of about $40 \mu \mathrm{m}$ the curvature driving force attains the same magnitude as the magnetic driving force, i.e. $\mathrm{p}_{\mathrm{c}} \cong 2 \mathrm{~kJ} . \mathrm{m}^{-3}$. The grains with orientations $\left(180,35, \varphi_{2}\right)$ are orientated favorably to minimize the magnetic contribution to the free energy and their growth is indeed enhanced - the size of these grains is distinctly bigger than the size of grains with orientations $\left(0,35, \varphi_{2}\right)$ (Table 1$)$. Furthermore, the grains with energetically favored orientations substantially outnumber the grains with unfavored orientations (Table 1). This can be attributed to the magnetically altered grain growth kinetics [19]. A similar behaviour, i.e. promotion of energetically favorably oriented grains both in size and number during magnetic annealing, has been encountered in $\mathrm{Ti}$ 
$[11,12]$, confirmed by computational analysis $[12,13]$ and can, therefore, be regarded as a quite classical behaviour.

Table 1. Grain numbers, grain number fractions (\% in brackets) and mean grain sizes for subsets based on orientation criteria in specimens annealed at $700^{\circ} \mathrm{C}$ for $180 \mathrm{~min}$ at zero field and in a magnetic field of $17 \mathrm{~T}$. Subsets of grains with favourable magnetic term in the free energy density are marked by a star $\left(\mathrm{C}^{*}, \mathrm{D}^{*}\right.$ and $\left.\mathrm{L}^{*}\right)$.

\begin{tabular}{|c|c|c|}
\hline Grain subsets & Out of magnetic field & In magnetic field \\
\hline $\begin{array}{l}\text { All measured grains } \\
\text { Overall mean grain size }\end{array}$ & $\begin{array}{l}10607 \\
21.6 \mu \mathrm{m}\end{array}$ & $\begin{array}{l}4857 \\
35.3 \mu \mathrm{m}\end{array}$ \\
\hline $\begin{array}{l}\text { Subset } \mathbf{A}(0,35,0) \\
\text { grains number (fraction\%) } \\
\text { mean grain size }\end{array}$ & $\begin{array}{l}510(6.6 \%) \\
25.6 \mu \mathrm{m}\end{array}$ & $\begin{array}{l}217(5.5 \%) \\
40.9 \mu \mathrm{m}\end{array}$ \\
\hline $\begin{array}{l}\text { Subset } \mathbf{B}(0,35,30) \\
\text { grains number (fraction\%) } \\
\text { mean grain size }\end{array}$ & $\begin{array}{l}1307(9.8 \%) \\
21.7 \mu \mathrm{m}\end{array}$ & $\begin{array}{l}585(7.4 \%) \\
30.8 \mu \mathrm{m}\end{array}$ \\
\hline $\begin{array}{l}\text { Subset } \boldsymbol{R} \text { (including } A+B) \\
\quad \text { grains number (fraction\%) } \\
\quad \text { mean grain size }\end{array}$ & $\begin{array}{c}5318(40.4 \%) \\
21.5 \mu \mathrm{m}\end{array}$ & $\begin{array}{c}1886(26.3 \%) \\
32.0 \mu \mathrm{m}\end{array}$ \\
\hline $\begin{array}{l}\text { Subset } \mathbf{C} *(180,35,0) \\
\text { grains number }(\text { fraction } \%) \\
\text { mean grain size }\end{array}$ & $\begin{array}{l}494(7.1 \%) \\
26.2 \mu \mathrm{m}\end{array}$ & $\begin{array}{l}378(15.9 \%) \\
48.9 \mu \mathrm{m}\end{array}$ \\
\hline $\begin{array}{l}\text { Subset } \mathbf{D} *(180,35,30) \\
\text { grains number (fraction } \%) \\
\text { mean grain size }\end{array}$ & $\begin{array}{l}1294(9.8 \%) \\
21.8 \mu \mathrm{m}\end{array}$ & $\begin{array}{l}788(14.7 \%) \\
36.3 \mu \mathrm{m}\end{array}$ \\
\hline $\begin{array}{l}\left.\text { Subset } \boldsymbol{L}^{*} \text { (including } C+D\right) \\
\text { grains number (fraction\%) } \\
\text { mean grain size }\end{array}$ & $\begin{array}{l}5289(59.6 \%) \\
21.7 \mu \mathrm{m}\end{array}$ & $\begin{array}{l}2971(73.7 \%) \\
37.4 \mu \mathrm{m}\end{array}$ \\
\hline $\begin{array}{l}\text { Grains of size }>70 \mu \mathrm{m} \\
\text { in subset } \mathrm{R}\end{array}$ & $\begin{array}{l}53(0.5 \%) \\
100.3 \mu \mathrm{m}\end{array}$ & $\begin{array}{r}89(1.8 \%) \\
93.1 \mu \mathrm{m} \\
\end{array}$ \\
\hline $\begin{array}{l}\text { Grains of size }>70 \mu \mathrm{m} \\
\text { in subset } \mathrm{L}^{*}\end{array}$ & $\begin{array}{r}59(0.6 \%) \\
104.2 \mu \mathrm{m} \\
\end{array}$ & $\begin{array}{r}296(6.1 \%) \\
105.8 \mu \mathrm{m} \\
\end{array}$ \\
\hline
\end{tabular}

The EBSD analysis also showed that the grain microstructure of the investigated $\mathrm{Zr}$ specimens after $700^{\circ} \mathrm{C}$ annealing is not uniform with respect to the grain size. Some grains grew essentially faster than the others (Table 1). The abnormally grown grains do present specific orientations, near $(0 / 180,35,0)$ in both sample annealed in and out of the field. These preferential orientations are rotated by $30^{\circ}<0001>$ as compared to the ODF maxima of the global texture of the sample annealed without field which are at $(0 / 180,35,30)$. We attribute the abnormal growth of these grains to the anisotropic behaviour of the grain boundaries, namely to the higher mobility of the boundaries between grains misoriented by $30^{\circ}$ around [0001]. We suggest that these boundaries migrate faster than the boundaries between grains of the major components $(0 / 180,35,30)$ due to their intrinsic properties, or as a result of anisotropy in the solute-boundary or particle-boundary interactions.

The magnetic field enhances the abnormal grain growth phenomenon. The number fraction of the abnormally grown grains is significantly higher in the sample annealed in the field $(7.9 \%)$ than without field (1.1\%) (Table 1). An increase in the fraction number of abnormally grown grains is observed for both favourably $(180,35,0)$ and unfavourably $(0,35,0)$ oriented grains. However, this increase is much more pronounced for the first than for latter grains. In addition, the abnormally grown grains differently oriented with regards to the magnetic field demonstrate a distinct difference 
in their mean size (Table 1). The difference in the size and number of the differently oriented abnormal grains is obviously caused by the impact of a magnetic driving force, which for large grains becomes predominant compared to the curvature driving force. As described above, the grains with the orientation $(180,35,0)$ are promoted for growth by the magnetic force, whereas grains with the orientation $(0,35,0)$ are retarded in their growth by this force.

\section{Acknowledgements}

One of the authors (DM) expresses his gratitude to the Deutsche Forschungsgemeinschaft for financial support. Part of this work was performed at the National High Magnetic Field Laboratory, which is supported by NSF Cooperative Agreement No. DMR-0084173, by the State of Florida and by the DOE. The investigated material was provided by Dr Pierre Barberis from the Cezus company.

\section{References}

[1] D. A. Molodov, G. Gottstein, F. Heringhaus and L. S. Shvindlerman: Scripta Mater. Vol. 37 (1997), p. 1207.

[2] D. A. Molodov, G. Gottstein, F. Heringhaus and L. S. Shvindlerman: Scripta Mater. Vol. 46 (1998), p. 5627.

[3] A. D. Sheikh-Ali, D. A. Molodov and H. Garmestani: Appl. Phys. Lett. Vol. 82 (2003), p. 3005 .

[4] P. J. Konijnenberg, D. A. Molodov and G. Gottstein: Mater. Sci. Forum Vol. 467-470 (2004), p. 763.

[5] A. D. Sheikh-Ali, D. A. Molodov, H. Garmestani: Scripta Mater. Vol. 48 (2003), p. 483.

[6] D. A. Molodov: Materials Science Forum, 2004, Vol. 467-470, p. 697-706

[7] D. A. Molodov, P. J. Konijnenberg: Z. Metallkd. Vol. 96 (2005), p. 1158-1165

[8] D. A. Molodov, P. J. Konijnenberg: Scripta Mater. Vol. 54 (2006), p. 977.

[9] W. W. Mullins: Acta Metall. Vol. 4 (1956), p. 421-432.

[10] D. A. Molodov, A. D. Sheikh-Ali: Acta Mater. Vol. 52 (2004), p. 4377.

[11] D. A. Molodov, P. J. Konijnenberg, N. Bozzolo, A. D. Sheikh-Ali: Mater. Letters Vol. 59 (2005), p. 3209.

[12] D. A. Molodov, Chr. Bollmann, P. J. Konijnenberg, L. A. Barrales-Mora, V. Mohles: Materials Trans. Vol. 48 (2007), p. 2800.

[13] L. A. Barrales-Mora, V. Mohles, P. J. Konijnenberg, D. A. Molodov: Comp. Mater. Sci. Vol. Vol. 39 (2007), p. 160.

[14] M. Dahms, H. J. Bunge: J. Appl. Cryst. Vol. 22 (1989), p. 439.

[15] M. Dahms: Appl. Cryst. Vol. 25 (1992), p. 259.

[16] N. Dewobroto, N. Bozzolo, P. Barberis, F. Wagner: Int. J. Mater. Res. Vol. 97 (2006), p. 826.

[17] F. Gerspach, N. Bozzolo, F. Wagner: Scripta Mater. Vol. 60 (2009), p. 203.

[18] D. A. Molodov, Chr. Bollmann, G. Gottstein: Mater. Sci. Eng. Vol. A 467 (2007), p. 71.

[19] D. A. Molodov, P. J. Konijnenberg, L. A. Barrales-Mora, V. Mohles: J. Mater. Sci. Vol. 41 (2006), p. 7853. 